\author{
신개념 백라이트유닛 모델링 \\ 이광훈 ${ }^{1} \cdot$ 지승현 ${ }^{2} \cdot$ 김수현 $^{2} \cdot$ 윤영수 $^{\dagger \dagger} \cdot$ 김수호 $^{3}$ \\ ${ }^{1}$ 건국대학교 신기술융합학과 \\ (ㅇ) 143-701 서울특별시 광진구 화양동 1 \\ ${ }^{2}$ 연세대학교 신소재공학과 \\ (ㅇ) 120-749 서울특별시 서대문구 신촌동 134 \\ ${ }^{3} \mathrm{GS}$ 칼텍스 신에너지연구센터 GS나노텍 \\ (우 143-031 서울특별시 강동구 성내 1동 453-2
}

(2009년 12월 14일 받음, 2010년 3월 10일 수정본 받음, 2010년 3월 15일 게재 확정)

백라이트유닛을 더 얇고 밝게 제안하기 위하여 우리는 새로운 타입의 백라이트유닛을 시뮬레이션하였다. 도광판 상면에 미세 볼록렌즈어레이를 형성시킨다. 또한, LGP와의 매칭을 위하여 우리는 기능성 광학 시트를 시뮬레이션하였다. 일반적으로 전통적 인 백라이트유닛들은 하나의 LGP와 네 개의 광학시트를 사용해왔으나 우리는 하나의 광학시트를 사용한 백라이트유닛을 시뮬레 이션하였다. 설계 결과 우리의 백라이트유닛은 동일한 발광성을 달성하면서 시야각은 $30 \%$ 더 좋아진 것을 밝혀내었다.

\title{
Modeling for New Type Backlight Units
}

\author{
Kwang-Hoon Lee ${ }^{1}$, Seung-Hyun $\mathrm{Jee}^{2}$, Soo-Hyun $\mathrm{Kim}^{2}$, Young-Soo Yoon ${ }^{2 \dagger}$, and Soo-Ho Kim ${ }^{3}$ \\ ${ }^{1}$ Department of Advanced Fusion Technology, Konkuk University, 1 Hwayang-dong, Gwangjin-gu, Seoul 143-701, Korea \\ ${ }^{2}$ Department of Material Science \& Engineering, Yonsei University, 134 Shinchon-dong, Seodaemun-gu, Seoul 120-749, Korea \\ ${ }^{3}$ GS nanotech, Caltex New Energy Development Center, 1 Seongnae-dong, Gangdong-gu, Seoul 143-031, Korea
}

(Received December 14, 2009; Revised manuscript March 10, 2010; Accepted March 15, 2010)

\begin{abstract}
In order to obtain thinner and brighter backlight units (BLU), we simulated a new-type backlight unit. A micro-lens array sheet was formed on the upper plane of the light guide plate (LGP) comprising the backlight unit. Also, in order to match with the LGP, we simulated a functional optical sheet. The conventional BLU uses one LGP and four optical sheets, but we simulated a BLU that uses one optical sheet. Simulation results have revealed that our BLU can achieve the same luminance and $30 \%$ better view angle as compared with conventional ones.
\end{abstract}

Keywords: Light guide plate (LGP), Backlight unit (BLU), Optical sheet, Mirco lens array (MLA), Axicon lens array (ALA) OCIS codes: (050.0050) Diffraction and gratings; (330.1710) Color, measurement; (160.3900) Metals; (240.6680) Surface plasmons

\section{I. 서 론}

디스플레이의 눈부신 발전은 인간생활에 큰 유익함을 가져 다주었다. 오늘날 디스플레이는 단순히 영상만을 표현하는 것이 아니라 영상 내에 내포된 정보를 가장 효과적으로 전달 하는 정보전달매체로서의 기능을 한다. 대표적인 정보전달 매체로서는 Liquid Crystal Display(LCD), Plasma Display
Panel(PDP), Cathode Ray Tube(CRT) 등이 있으며 현재는 $\mathrm{LCD}$ 의 보급율이 증가추세를 보이고 있다. $\mathrm{LCD}$ 는 비 자가 발광 형태의 구동원리를 따르고 있으며, 구성요소로서는 크 게 광원부와 표시부로 구분되어진다. 일반적으로 광원부는 백라이트유닛(BLU:Back Light Units)이라 하는 구성요소로 대표될 수 있으며, 이 구성요소는 표시부의 일정 크기의 면 광원 형태로 전환하여 주는 것을 담당한다. 그리고 표시부는

${ }^{\dagger}$ E-mail: yoonys@yonsei.ac.kr

Color versions of one or more of the figures in this paper are available online. 
색을 표시할 수 있는 컬러필터(Color Filter) 와 백라이트유닛 으로부터 오는 빛을 개폐할 수 있는 TFT(Thin Film Transistor) - Array로 이루어져 있다. 본 논문에서는 비 자가발광 형태 인 LCD에서 매우 중요한 광원부의 역할을 하고 있는 백라 이트유닛 부분만을 언급하려 한다. 특히, 백라이트유닛은 $\mathrm{LCD}$ 의 휘도 및 균일도를 조절하는 중요한 기능을 맡고 있 다. 세부적인 구성요소로는 광원(Light Source)과 면광원기능 의 도광판(LGP: Light Guide Plate), 중심시야각 확보를 위한 여러 광학필름(Optical Film)들이 있다 ${ }^{[1-3]}$. 이러한 구성요소 중 도광판은 휘도 증가를 위한 1 차적인 중요 구성요소로서 도광판 내로 입사된 광속(flux)은 도광판의 기하학적 구조에 따라 LCD 표시부와 인접한 도광판 상면으로 출사하게 된 다. 대표적인 기하구조로서는 산란방식의 산란인자패턴(Dot Pattern)과 전반사(Total Reflection)식이 있다. 이 두 가지 모 델 모두 도광판 내로 입사된 광속이 내부 임계각 조건을 만 족하여 도광판 상면으로 투과 할 수 있도록 설계된다.

산란자 모델은 높은 균일도 및 양산이 용이하다는 장점이 있지만, 다중의 광학필름이 사용되고, 도광판으로부터 출사 하는 큰 고도각의 광속으로 인하여 도광판 상면의 법선방향 으로 중심출사하는 광속량이 적은 단점이 있다. 반면에 직반 사 모델은 산란자에 의해 손실되는 광량을 줄이고, 광속의 중심출사량을 직접 반사시켜 높은 휘도를 갖는다는 장점이 있으나, 도광판의 국부지역에서의 높은 휘도, 이에 따른 균 일성의 저하 그리고 제조상의 어려움, 고가의 장비필요 등과 같은 단점이 있다. 이러한 이유로 본 연구에서는 높은 균일 도 및 양산성이 용이한 산란자 모델을 기반으로 도광판 상면 에 미세볼록렌즈어레이(MLA:Micro Lens Array) ${ }^{[4-5]}$ 를 형성 시키고, 미세원뿔렌즈어레이(ALA: Axicon Lens Array)가 형 성된 광학필름으로 구성된 새로운 백라이트유닛을 제시하고 자 한다.

\section{II. 실 험}

본 실험 - 시뮬레이션 - 을 통하여, 상용화되고 있는 기존 의 백라이트유닛 및 새롭게 제안된 백라이트유닛의 구조적, 광학적 특성을 비교하여 제안된 백라이트유닛의 장점을 정

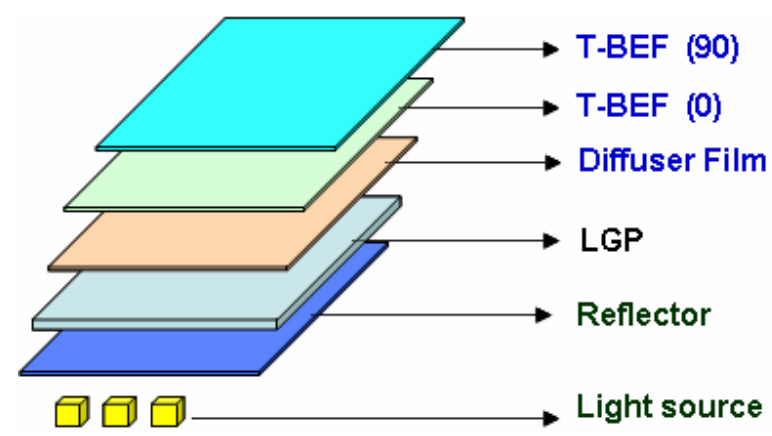

FIG. 1. The structure of conventional backlight units.
량적으로 기술하고자 한다.

\section{1. 백라이트유닛 구조}

현재, 백라이트유닛은 광원의 위치에 따라 직하형(Direct type)과 사이드형(Side type)으로 분류되며, 이중 사이드형은 도광판의 형상에 따라, 다시 직선형(Straight Type)과 쐐기형 (Wedge Type)으로 구분된다. 일반적으로 백라이트 유닛의 구성은 광원과 도광판 그리고 도광판을 출사한 광속을 균일 하면서 집광시키는 기능을 담당하는 광학필름으로 나뉜다. 그림 1은 일반적인 백라이트유닛의 구조를 나타내고 있다. 광원은 크게 CCFL(Cold Cathode Fluorescent Lamp)와 LED (Light Emitting Diode)가 사용된다. 최근에는 환경문제 및 제품의 크기, 제조단가 등을 고려하여 LED가 주로 사용되고 있다. 백라이트유닛에서 핵심적인 기능을 하는 도광판(LGP: Light Guide Plate)은 주조가 용이하고, 높은 광투과율을 갖는 PMMA(Polymethyl Methacrylate) 또는 PC(Polycarbonate)가 사 용되며, 점광원을 면광원으로 변환시키는 목적을 갖고 있다. 면광원으로 변화시키기 위하여, 도광판 하면에는 광원으로부 터 출사된 광속이 넓은 면적으로 산란될 수 있도록 일정 지 름을 갖는 점(dot) 형태의 산란인자들을 형성한다. 산란자들 은 도광판 상면으로 고루 출사하기 위하여 도광판 하면 전체 에 밀도별 분포를 한다. 산란자 밀도는 광원에서 멀어지는 장축 방향으로 증가한다. 그림 2 는 도광판 장축방향으로 분 포되는 산란자 밀도 및 순수 도광판내에서의 출사광량의 세 기를 나타낸다.

효율적인 광속사용을 위하여, 도광판 하면과 인접한 위치 에 반사필름(반사율 $98 \%$ 이상)을 삽입하여 도광판 하면방향 으로 투과하여 손실되는 광량을 방지하고, 이를 반사시켜 다 시 상면으로 재입사 시키는 방법을 택하였다. 이렇게 반사되 어 도광판 내로 입사된 광속은 입계각 조건을 만족할 경우 상면으로 출사하게 된다. 일반적으로, 매질이 다른 물체가 접해 있을 때, 두 매질의 경계면에서는 굴절현상이 일어난다. 특히 밀한 매질에서 소한 매질로 광속이 진행하는 경우, 두 매질의 굴절률 차에 따른 임계각이 형성되고 임계각 이상의 입사각을 갖는 광속은 경계면을 투과하지 못한다. 그림 3은 이를 나타낸 모식도이다. 일반적인 백라이트유닛에서 도광판

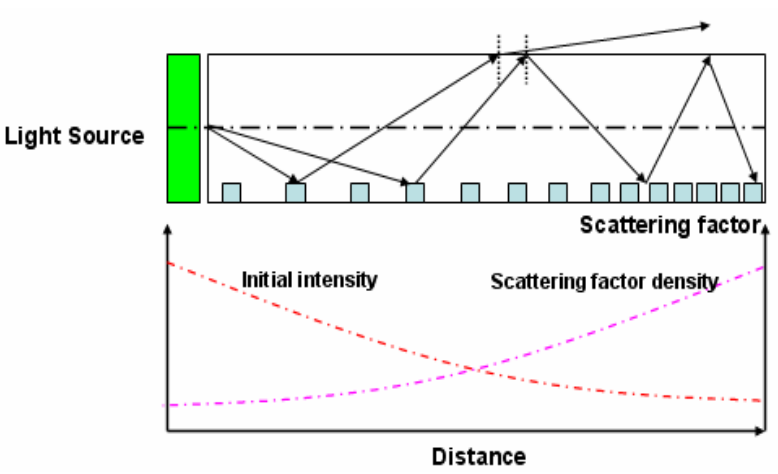

FIG. 2. The principle of scattering factor density control. 


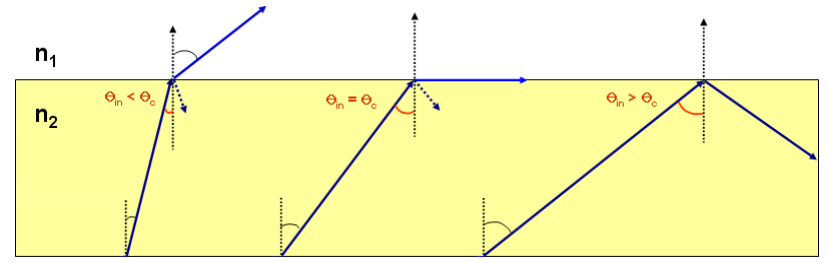

FIG. 3. The phenomena of transmission and reflection.

내의 광속은 다음과 같은 과정을 거처 LC 패널로 입사한다. 도광판의 상면으로 진행하는 임계각 이내의 광속들은 경계 면을 투과하여 인접한 확산 필름(Diffusion Film)를 지나 산 란된다. 산란된 광속들은 확산판의 확산도(HAZE)에 비례하 여 경계면에 수직한 법선 방향으로 집광되는 효과를 갖는다. 좀 더 효과적인 집광을 위하여 서로 직교하는 2장의 프리즘 형태의 광학필름(Prism Film)이 사용되고, 이를 투과한 광속 들은 최종적으로 $\mathrm{LC}$ 패널에 입사하게 된다.

현재, 이러한 백라이트유닛에 이용되고 있는 주요 핵심부 품들 즉 광학필름들 주로 외산에 의존하고 있다. 특히, 확산 및 프리즘 방식의 핵심기술은 일본 및 미국이 특허권을 보유 하고 있어, 이를 국내에서 사용하는데 큰 제약을 받고 있다. 그러나 이러한 외산제품의 특허를 침해하지 않고, 이들과 동 일하거나 우수한 광학적 특성의 제품을 개발하는 연구가 이 루어지고 있으며, 일부 상용화 되고 있다. 또한, 광원의 광량 손실을 최소화 하고 고휘도를 구현하기 위한 연구가 진행되 고 있으며, 이에 대한 핵심기술로서 미세광학소자 설계기술 이 주목 받고 있다. 예로서 중대형 도광판의 하면 산란인자 형성기술 및 소형 도광판의 V-Groove 형성기술 등을 들 수 있다. 특히 V-Groove 인자가 적용된 도광판의 경우, 산란인 자 대비 $20 \%$ 이상의 우수한 광특성(Optical property)을 나타 내고 있다. 그러나, 이는 V-자를 형성하기 위한 장비의 가격 이 매우 고가이고, 제작에 대한 구속조건이 매우 까다로우며, 최종 시야각 및 휘선(White line)등의 광학적 문제점 등이 지 적되고 있다.

이에 본 연구의 목적은 기존의 산란인자 도광판을 기본으 로, 도광판 상면에 미세볼록렌즈어레이를 형성하고, 미세원 뿔렌즈어레이가 형성된 광학판의 조합을 통하여 기존의 유 닛 보다 광특성이 개선된 새로운 타입의 백라이트유닛 구성 을 모델링 하는데 있다. 평가 방법으로서, 기존 및 제안된 모 델에의 휘도 및 시야각을 정량화하고 이를 비교하여 제안된 유닛의 개선 여부를 평가하였다.

\section{2. 백라이트유닛의 광 시뮬레이션 모델링.}

본 연구에서 이용한 광시뮬레이션 프로그램은 [SPEOS]이 다. 우선, 기존 백라이트유닛의 광학적 특성을 분석하기 위 하여 현재, 상용화되고 있는 백라이트유닛의 구조 및 하면 산란인자를 설계하여 SPEOS로 전산모사 하였다. 전산모사 에 사용된 기존 백라이트유닛 구속조건은 다음과 같다. 도광 판의 두께는 $0.6 \mathrm{~mm}$ 이고, 직선형 도광판이다. 확산필름은

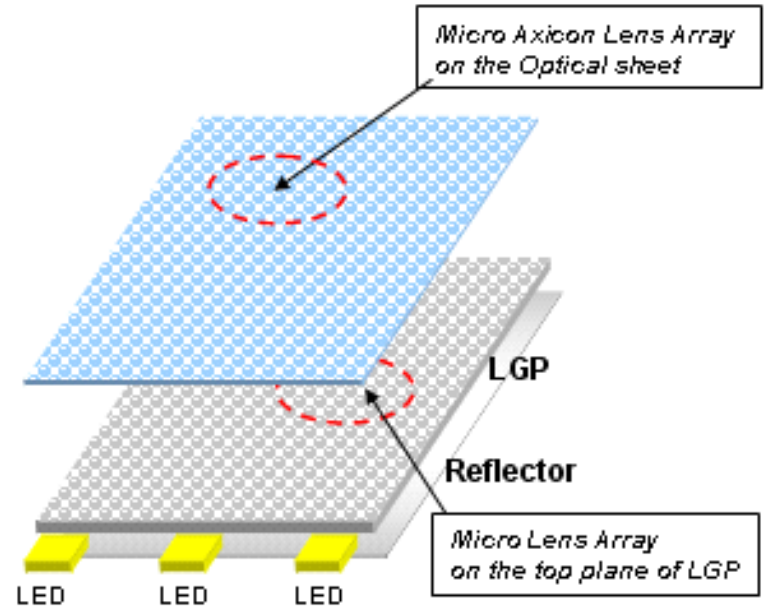

FIG. 4. New structure of backlight unit.

$82 \%$ 의 확산도의 특성을 갖도록 설계하였고, 집광필름과 반 사 필름은 $3 \mathrm{M}$ 사의 Thin $\mathrm{BEF}$ (Brightness Enhancement Film) 와 $\operatorname{ESR}(E n h a n c e m e n t$ Specular Reflection) 필름 특성을 참조 하여 설계하였다. 광원은 백색광을 갖는 3 개의 Chip-LED 타 입의 점광원으로 설계하였다. 광원과 도광판 사이의 간격은 500 um로 설계하였다.

그림 4는 본 연구에서 제시하고자 하는 새로운 백라이트구 조를 보여 주고 있다. 우선, 도광판은 하면과 상면을 구분하 여 설계하였다. 도광판 상면에는 미세볼록렌즈어레이가 삽입 되었으며, 도광판 하면에는 기존 백라이트 유닛 모델에서 이 용한 산란인자패턴을 이용하였다. 광학필름은 미세원뿔렌즈 어레이가 삽입된 광학필름으로 모델링하였다. 이는 $\mathrm{LC}$ 패널 로 삽입되는 최종 출사 광분포를 형성하기 위한 것이다. 세 부적으로 기술하면, 도광판 상면에 형성된 미세볼록렌즈어레 이를 투과한 광속들은 미세원뿔렌즈어레이가 형성된 광학판 을 투과하여 기존의 백라이트유닛에서 최종 출사된 광속분 포와 유사한 특성을 갖도록 설계하였다. 따라서 제안된 백라 이트유닛은 광학적 특성면에서, 마이크로렌즈어레이가 삽입 된 도광판으로 인해 출사광속의 집광도가 향상되고, 구성 면 에서, 원뿔 렌즈 어레이가 삽입된 한 장의 광학필름으로 기 존의 광학필름들을 대처할 수 있어, 백라이트 유닛의 경박단 소가 가능하고, 제조단가의 저하가 가능하다. 이를 검증하기 위하여 기존 백라이트 모델 및 제안된 방법의 특성을 시뮬레 이션하였다.

미세볼록렌즈의 구조는 직경이 $10 \mathrm{um}$, 높이가 $10 \mathrm{um}$ 로서, 종횡비(Aspect Ratio)가 1인 구조로 설계하였으며, 활성화를 위한 구성으로서, 미세볼록렌즈릿(Micro convex lenslet)의 중심간 배열이 육각형 형태인 Hexagonal 배열을 채택하여 렌즈간 간격의 공백을 최소화 하였다. 또한, 본 연구에서 제 시한 광학필름에 형성된 미세원뿔렌즈의 구조는 직경이 10 um이며, 높이가 7 um인 원뿔형태이다. 원뿔렌즈릿의 배열은 도광판 상면의 미세볼록렌즈릿의 활성화 구조와 같다. 미세 볼록렌즈 및 미세원뿔렌즈의 구조는 표 1 에 제시하고 있다. 
TABLE 1. MLA and ALA specification

\begin{tabular}{c|c|c|c|c}
\hline \hline & Diameter & Height & Fill Factor & Figure \\
\hline MLA & $10 \mathrm{um}$ & $10 \mathrm{um}$ & $100 \%$ & \\
\hline ALA & $10 \mathrm{um}$ & $7 \mathrm{um}$ & $100 \%$ &
\end{tabular}

광 시뮬레이션 변수인 광선(Optical Ray)의 수는 200,000 개로 하였으며, 신뢰성 있는 검증을 위하여 동일한 광선의 수를 이 용하여 5 회 반복 수행하였다. 이렇게 반복 실험한 결과는 $5 \%$ 이내의 오차 범위이며, 이는 SPEOS 내부 광선발생 알고리듬 에 기인한다. 시뮬레이션을 통해 획득한 각 유닛 별 광학적 특성 값은 5 회 반복한 결과의 평균값으로 정량화하였다.

\section{III. 결과 및 고찰}

그림 5 는 기존 백라이트유닛과 본 연구에서 새롭게 제시하 고자하는 백라이트유닛에서 도광판을 통과하여 출사되어진 광학적 특성의 결과를 보여 주고 있다. 결과에서 볼 수 있듯 이, 기존 하면 산란인자가 형성된 도광판에서는 상면으로부 터 투과하여 나오는 광속의 출사각이 상면의 법선과 80 도 이 상의 큰 각을 이룬다. 이러한 결과는 도광판 하면의 산란인 자를 지나 산란되어 도광판 내로 입사되는 광속들이 임계각 근처의 입사각을 갖고 있음을 의미한다. 따라서 도광판 상면 을 투과하여 출사하는 대부분의 광속들은 경계면의 법선 방 향으로 집광되지 못하므로 낮은 광효율을 갖게 된다. 이에 반해 새롭게 제시한 미세볼록렌즈어레이가 삽입된 도광판의 경우, 출사되는 광속들은 좌우 30 도 정도의 링(Ring) 형태의 광분포를 나타내고 있다. 이는 상면에 삽입된 미세볼록렌즈 어레이에 의해서 도광판 상면으로부터 출사하는 광속의 집 광도가 향상된 것이다. 이러한 결과로 인하여 주각은 상면의 법선과 이루는 30 도 부근으로 출사되어지는 결과를 나타내 고 있다. 또한, 본 연구에서 제시한 활성화범위가 $100 \%$ 인 요 소 역시 이러한 결과를 나타내는데 중요한 변수로 작용한 것 으로 사료된다.

이러한 광 특성을 보이는 기존 도광판과 본 연구에서 제시 한 도광판 상면에 기존 광학필름들과 본 연구에서 제시한 미 세원뿔렌즈어레이가 형성된 광학필름을 각각 조화시켜 모델 링하였다. 그림 6 은 이러한 구조를 이용하여 광 시뮬레이션 을 구동한 결과를 보여 주고 있다. 결과에서 볼 수 있듯이 기존 백라이트 유닛은 3장의 광학필름(확산필름 1장, 집광필 름2장)을 이용 하였을 때 가장 높은 중심출사광의 특성을 보 이는 반면에, 본 연구에서 제시한 백라이트유닛은 1장의 광 학필름을 이용하여 기존 백라이트와 유사한 중심출사광의

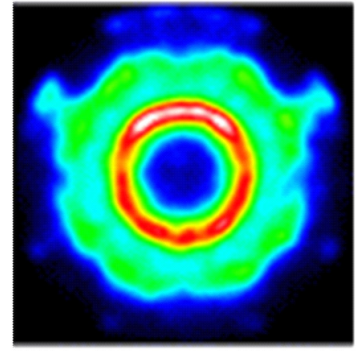

(a)

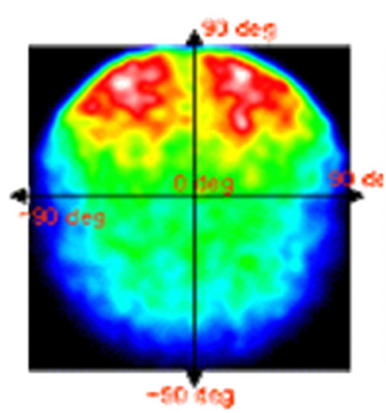

(c)

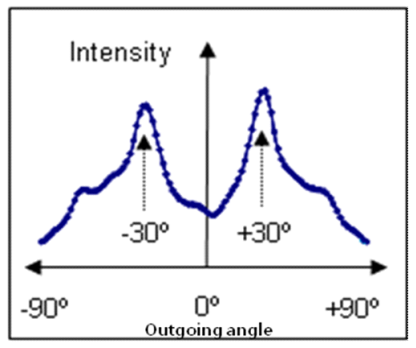

(b)

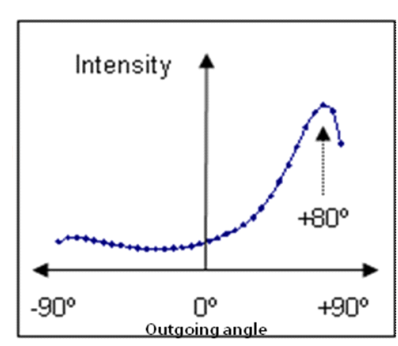

(d)
FIG. 5. The optical emitting results of LGP: (a) and (b) are the images for conventional type LGP, (c) and (d) for new type LGP.

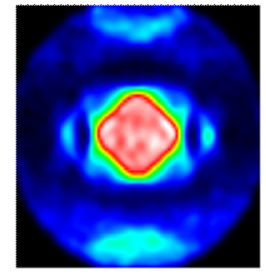

(a)

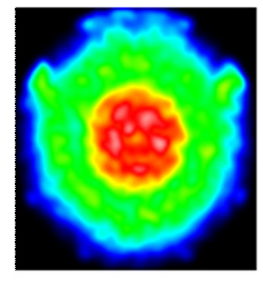

(c)

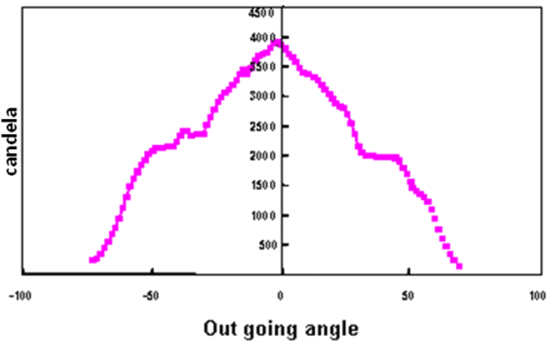

(b)

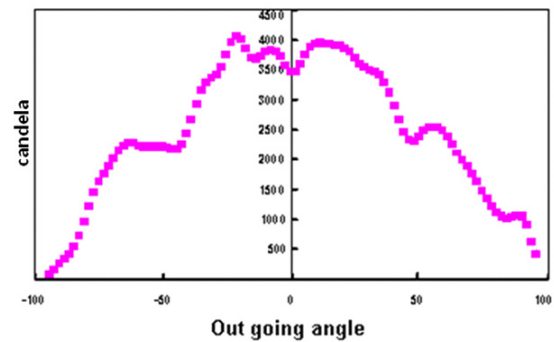

(d)
FIG. 6. The optical emitting results of BLU: (a) and (b) are the images for conventional type BLU, (c) and (d) for new type BLU.

특성을 보이는 것으로 나타났다. 또한, 최종적으로 형성된 백라이트유닛의 시야각 분석결과, 기존 백라이트유닛의 시야 각은 FWHM(Full Width Half Mmaximum)값을 기준으로 판 단하여 30 도 인데 비하여 본 연구에서 제시한 백라이트유닛 의 시야각은 50 도 인 것으로 나타났다. 이러한 결과는 기존 
백라이트 구조 대비 고휘도, 초박형, 저단가의 백라이트유닛 모델을 제시할 수 있는 가능성을 대변한다.

\section{IV. 결 론}

경박단소(輕薄短小)화 되어가는 디스플레이 기술적 경향 에 맞추어 본 연구는 기존의 백라이트유닛과 비교하여 초박 형, 고휘도, 저가격의 제품으로 활용될 수 있는 새로운 개념 의 백라이트 유닛을 모델링하였다. 도광판 부분은 기존의 도 광판 하면 산란인자 패턴을 이용하여 상면에 미세볼록렌즈 어레이가 형성된 도광판을 모델링하였고, 이와 조화를 이루 기 위하여 미세원뿔렌즈어레이가 삽입된 광학필름을 모델링 하여 기존 백라이트 유닛과 유사한 휘도값과 $30 \%$ 이상의 우 수한 시야각 특성등의 우수한 광학적 특성을 보이는 백라이 트 유닛을 모델링 하였다. 그러나 균일도 측면에서, 제안된 백라이트유닛의 균일도(Uniformity)는 기존의 유닛과 비교하 여 정확한 시뮬레이션의 비교가 불가하였다. 이유로는 도광 판 상면으로 출사하는 광속의 집광도를 높이기 위하여 형성 시켰던 미세볼록렌즈 및 미세원뿔렌즈어레이의활성화 간격 (10 um)이 미산란효과(Mie scattering effect)를 유발하는 것으
로 사료되기 때문이다. 이 간격은 기하광학 기반의 광선추적 시뮬레이션 툴로서는 예측할 수 없는 미산란효과 영역이기 때문에 회절광학을 기반한 시뮬레이션이 요구된다. 이에, 현 재 회절 및 산란효과가 균일도에 미치는 영향을 연구 중에 있다.

\section{References}

1. M. Anandan, "LCD Backlighting," Society for Informational Display Seminar Lecture Notes, 169-250 (2002).

2. K. Kalantar, "Optical design of light-guide plates for illumination systems used in mobile phones and PDAs," Asia display, IDW 2001, 517-520 (2001).

3. D. M. Brown, R. Dean, and J. D. Brown, "LED backlight : design, fabrication, and testing," Proc. SPIE 3938, 180-187 (2000).

4. T. R. Jay, M. B. Stern, and R. E. Knowlden, "Effect of refractive microlens array fabrication parameters on optical quality," Proc. SPIE 1751, 236-245 (1992).

5. K. H. Hong, "Design of Micro lens array," J. Opt. Soc. Korea 5, 204-211 (1994). 